\title{
АКТУАЛЬНІ ПРОБЛЕМИ ВАЛЕОЛОГІЧНОГО ВИХОВАННЯ СТУДЕНТІВ В УМОВАХ ЗМІШАНОГО НАВЧАННЯ
}

8. Die besten Hochschulen in Deutschland. Stern. 2001. Heft 17. S. 57-68.

\section{REFERENCES}

1. Kaidalova, L. H., Shchokina, N. B. \& Vakhrusheva, T. Yu. (2009). Pedahohichna maisternist vykladacha: navch. posib. [Pedagogical skills of the teacher: textbook. way.]. Kharkiv, 140 p. [in Ukrainian].

2. Kontseptsiia pedahohichnoi osvity (1998). [The concept of pedagogical education]. Kyiv. [in Ukrainian].

3. Osnovy pedagogicheskogo maysterstva (1987). [Fundamentals of pedagogical skills]. (Ed.). I. A. Zyazyun. Kyiv, 205 p. [in Russian].

4. Sovremennye sistemy povysheniya kvalifikatsii prepodavateley vuzov [Modern systems of professional development of university teachers]. Available at: http:// www.vfmgiu.ru/Higher-education-in-Russia/ Systemsimprovement-professional-skill-teachers-of-highschools/index. html [in Russian].

5. Maksimenko, S. D. \& Osedlo, V. I. (2011). Subektnyy podkhod $\mathrm{v}$ izuchenii professionalnoy samorealizatsii
[Subjective approach in the study of professional selfrealization]. Psychology and Law. No. 1. p.1. Available at: http://psyjournals.ru/psyandlaw/2011/n1 / 39330.shtml [in Russian].

6. Chorna, O. (2010). Suchasni tendentsii pidhotovky ta pidvyshchennia kvalifikatsii vykladachiv VNZ (na prykladi vidpovidnoho dosvidu Velykoi Brytanii). [Modern trends in training and retraining of university teachers (on the example of the relevant experience of Great Britain)]. Scientific notes Series: Pedagogical sciences. Kirovograd, Vol. 88. pp. 273-276. [in Ukrainian].

7. Yarochkina, G. V. (2008). Innovatsionnaya model povysheniya kvalifikatsii pedagogicheskikh kadrov uchrezhdeniy dovuzovskogo professionalnogo obrazovaniya [Innovative model of professional development of teachers of pre-university vocational education]. Innovations in education. pp. 4 - 13. [in Russian].

8. Die besten Hochschulen in Deutschland [The best high schools in Germany]. Stern. 2001. Vol. 17. pp. 57-68. [in German].

УДК 378

DOI:

Ігор Шупік, кандидат технічних наук, доцент, дочент кафедри енергетики,електротехніки і фізики Херсонського національного технічного університету

\section{АКТУАЛЬНІ ПРОБЛЕМИ ВАЛЕОЛОГІЧНОГО ВИХОВАННЯ СТУДЕНТІВ В УМОВАХ ЗМІШАНОГО НАВЧАННЯ}

У статті висвітлена проблема збереження здоров'я студентів в умовах змішаного та дистаниійного навчання. Описано аналіз досвіду та результати дослідження чинників, які є причиною погіриення стану здоров'я студентів під час організачії дистаниійного і зміманого навчання.

Зосереджено увагу на шляхах розв'язання завдань валеологічного виховання студентської молоді у закладах вищої освіти, обгрунтовано умови зміцнення здоров'я студентів, та формування у них усвідомлення необхідності дбати про стан здоров'я.

Наголошено на необхідності підтримки і бажання у студентської молоді бути здоровими, а також формування вміння і навичок дотримання здорового способу життя.

Ключові слова: валеологічне виховання; дистанційне навчання; проблеми виховання; валеологія; валеологічна підготовка; здоров'я людини; здоровий спосіб життя.

Jim. 10.

Igor Shupik, Ph.D.(Technical Sciences), Associate Professor, Associate Professor of the Energy, Electrical Engineering and Physics Department, Kherson National Technical University

\section{CURRENT PROBLEMS OF VALEOLOGICAL EDUCATION OF STUDENTS IN THE CONDITIONS OF MIXED LEARNING}

The article considers the problem of preservation of students' health in the conditions of mixed and distance learning. The analysis of experience and the results of the research of the factors that cause the deterioration of students' health during the organization of distance and mixed learning are described.

The focus is on solution of the problems of valeological education of students' youth in higher education institutions.

One of the urgent tasks of valeological education is the formation of valeological culture of the student. Its formation must contain such a structural component of the educational process as the impact on the consciousness and behavior of the students' youth, because it is impossible to force the student to use the methods and techniques of health care systematically.

(C) I. Шупік, 2021 


\section{АКТУАЛЬНІПРОБЛЕМИ ВАЛЕОЛОГІЧНОГО ВИХОВАННЯ СТУДЕНТІВ В УМОВАХ ЗМІШАНОГО НАВЧАННЯ}

So as to the educational process in higher education institutions in these conditions of learning to meet the norms of strengthening the health of students, it is necessary to care of the formation of each student's awareness in the need of caring for their health, creating of appropriate psychological and pedagogical conditions for support and desire of the students' youth to be healthy, as well as to form the skills and abilities to follow a healthy lifestyle for the benefit of their own health. Only those ways that indirectly motivate the student to self-development, selfeducation of their personal qualities, which will help them to have a certain level of valeological culture, will be effective and efficient.

The following conditions for students' health protection in the process of mixed learning are defined: the creation of a positive psychological microclimate that effectively affects the educational process and the health of students; the use of appropriate methods and programmes; creation of an information space on the issues of health preservation of the students' youth; increasing of the motor activity; compliance of sanitary and hygienic mode.

Keywords: valeological education; distance learning; problems of education; valeology; valeological training; human health; healthy lifestyle.

П остановка проблеми. В умовах сьогодення суттєво актуалізується проблема збереження та зміцнення здоров’я студентської молоді. Як зсвідчують результати наукових досліджень, "молодь сьогодні проводить вільний час інакше, а суттєвою різницею є використання під час ігор алкоголю, тютюну, наркотиків. Відсутність руху, вправ і загалом рухливої активності є причиною різних видів хвороб: ожиріння, проблеми з хребтом, серцем, дихальними шляхами, голово-кружінням, а також психічного харектеру" [10].

Спостереження за освітнім процесом у 3ВО дають підставу стверджувати, що помітно збільшується число студентів, які за станом здоров'я $\epsilon$ спеціальною медичною групою, або взагалі звільнені від занять фізичною культурою. Розв'язання вказаної проблеми вчені О. Тимошенко, Е. Вільчковський, Г. Григоренко, О. Дубогай, C. Канішевський, багато в чому пов'язують 3 необхідністю підвищення ефективності системи фізичного і валеологічного виховання.

Завданням закладів вищої освіти є підготовка компетентного професіонала, який може презентувати свою професійність на ринку праці, а також формування здорового громадянина. Тому актуальною стає проблема використання здоров'язбережувальних технологій в освітньому процесі вишів та пропаганда серед студентів здорового способу життя.

У більшості закладів вищої освіти питання, пов'язані зі здоров'ям студентської молоді, висвітлюються на заняттях 3 навчальних дисциплін. Водночас не завжди проводиться постійна й систематична робота 3 озброєння студентів уміннями та навичками дотримання здорового способу життя.

Ця проблема має розв'язуватися послідовно систематично при активній дії усіх учасників освітнього процесу, що сприятиме створенню відповідного середовища для формування таких важливих життєвих навичок, які можуть спонукати студентську молодь до збереження, зміцнення й відтворення здоров'я, і головне, орієнтувати на реалізацію здорового способу життя. Особливо важливим є формування мотивації у студентів щодо збереження власного здоров'я й відповідального ставлення до нього. Майбутні фахівці мають усвідомлювати, що ніякі ліки не спроможні зробити їх цілковито здоровими.

Аналіз останніх досліджень і публікацій. Проблему формування валеологічної культури особистості досліджують різні галузі наук: лікувальна медицина, фізіологія, психологія, педагогіка, методика фізичної культури. Учені стверджують, що здоров'я людини не може визначатись тільки констатацією відсутності хворі. На думку науковців, “Здоров'я - це стан, який дозволяє людині вести вільне, без будь-яких обмежень, життя, повноцінно виконувати притаманні людині функції, перш за все, трудові, вести здоровий спосіб життя, тобто відчувати душевне, фізичне та соціальне благополуччя" [8].

У дослідженнях Л. Сущенко, В. Мухін, О. Міхеєнко наголошують на загальних підходах до технологій формування валеологічного світогляду й основ здорового способу життя студентів. О. Верхорубова зазначає, що завдання валеологічного виховання можуть бути виконані тільки тоді, коли буде доцільне поєднання психолого-педагогічного та медико-біологічних підходів, а в основі формування культури здоров'я студентської молоді - фізична культура.

I. Адєєнко зазначає, що проблема розвитку культури здоров'я сучасної молоді у закладах вищої освіти має свої психологічні принципові особливості, які “пов'язані з тим, що неможливо примусити студента системно оволодіти способами і прийомами здоров' язбережувальної діяльності. Придатними можуть бути лише такі шляхи, які стимулюють студента опосередковано, активізують його як суб'єкта свого інтелектуального і професійного становлення, розвитку й саморозвитку. Тобто процес розвитку культури здоров'я студентів має бути спрямований, насамперед, на розвиток їхніх 


\section{АКТУАЛЬНІ ПРОБЛЕМИ ВАЛЕОЛОГІЧНОГО ВИХОВАННЯ СТУДЕНТІВ В УМОВАХ ЗМІШАНОГО НАВЧАННЯ}

особистісних якостей як майбутніх фахівців" [1]. Зокрема, коли моя йде про дистанційне, або змішане навчання у вишах, викає потреба у реалізації вольових якостей особистості, прояву стійкого пізнавального інтересу та відповідних моральних аспектів комунікативності.

Одним із головних завданнь професійної освіти, в контексті зазначеної проблеми, $є$ формування у студентської молоді стійкого інтересу до здоров'язбережувальних проблем, визнання їх необхідності.

У процесі професійної освіти у студентів формується установка на здоров'язбереження як важливу діяльність, яка сприяє зміцненню їх здоров'я та навколишніх. Як зазначає В. Оржеховська можна визначити, що “розвиток культури здоров'я - це процес і результат цілеспрямованого й організованого оволодіння цілісністю поняття “'здоров’я”, “Зздоровий спосіб життя”, стійкимиособистіснимиздоров'язбережувальними рисами і якостями, необхідними для успішної життедіяльності [6].

Студенти, які вирішили дотримуватися здорового способу життя, мають низку питань. Найпоширеніші серед них - організаційні, зокрема, незнання з чого починати. Теоретики та практики, які досліджують ці проблеми, стверджують, що, варто почати з відмови від шкідливих звичок, дотримуватися правильного харчування, здійснювати регулярно прогулянки на свіжому повітрі і скорочувати час, проведений за комп'ютером. Але, як вже зазначалося, зробити це нелегко, тому що часто відсутність вольових якостей заважає підтримувати здоровий спосіб життя.

Дослідження психологів доводять, що невідповідний емоційний настрій, недостатність пізнавальної мотивації та лінощі заважають студентам як у навчанні, так і забезпеченні здорового способу життя.

Як стверджують Т. Христова, В. Пюрко, С. Казакова, під час організації дистанційного навчання вплив несприятливих соціальногігієнічних чинників призводить до негативних тенденцій у стані здоров'я студентської молоді. Основними факторами захворюваності неінфекційними хворобами $є$ низька рухова активність, нервово-емоційна перенапруга, шкідливі звички [9].

В українській науці питання збереження здоров'я студентської молоді в умовах інтенсифікації навчання та інформаційних перевантажень висвітлюються в працях Ю. Бойчука, Н. Науменко, В. Грибан, В. Кофанова та ін. [2; 3; 4].

За результатами дослідження А. Яновського, серед загроз інформаційного середовища, що впливають на особистість, пї загальне й психологічне здоров'я можна виокремити фізіологічні: функціональні порушення органів зору, опорно-рухової, серцево-судинної, нервової, імунної систем та психічні захворювання.

Отже, можемо зазначити, що існує багато аспектів вказаної проблеми. Важливо шукати шляхи її подолання, тому що саме від цього буде залежати формування здорової, успішної студентської молоді.

Мета статті - дослідження шляхів розв'язання актуальних проблем валеологічного виховання студентської молоді в умовах змішаного навчання.

Виклад основного матеріалу. Теоретичний аналіз літературних джерел та практичний досвід організації змішаного навчання студентів допоміг нам дослідити проблеми валеологічного виховання та шляхи їх подолання у закладах вищої освіти.

Можемо констатувати, що сучасній Україні помітно погіршується економічна, соціальна та екологічна ситуація, падає рівень здоров'я населення. Недостатня рухова активність гіпокінезія, яка $є$ передумовою найбільш масових захворювань, уражає дітей та молодь. Багато в чому це пов'язано з тим, що пропаганда оздоровчих знань ведеться у формі рекомендацій, “готових до споживання” без будь-яких розумових зусиль та застосування індивідуального підходу до дітей і молоді [5; 6].

Нами було проведено анкетування серед студентів Херсонського Національного технічного університету (182 особи) з метою вивчення їх ставлення до валеологічної культури. Аналіз анкетних даних засвідчив, що поняття валеологічної культури 65 \% студентів розуміють як дотримання здорового способу життя, але переважальна більшість (66 \%) респондентів пов'язують це поняття із заняттями спортом, $40 \%$ - 3 відсутністю шкідливих звичок, 41 \% повноцінним харчуванням, 16 \% відповідним режимом дня. На поставлене нами запитання "Чи дотримуєтеся Ви здорового способу життя" студенти відповіли так: $54 \%$ - дотримуються, дотримуються інколи - 24 \%, не дотримуються - $22 \%$. Серед причин, які заважають дотримуватися здорового способу життя, студенти називають: відсутність стійких переконань, матеріальні проблеми, відсутність певних вольових якостей. Крім того значний відсоток респондентів причиною визначили методику організації змішаного навчання, зокрема, значну витрату часу. Можемо констатувати, що 
тільки половина студентів дотримуються здорового способу життя, а причини його недотримання переважно є суб' єктивними.

Поряд із формуванням пізнавальної мотивації, самоорганізації студентської молоді гостро стоїть проблема організації роботи щодо формування здорового способу життя в умовах змішаного навчання.

Щоб освітній процес у зазначеному контексті відповідав вимогам зміцнення здоров'я, заклади вищої освіти повинні подбати про формування у студенті усвідомлення необхідності дбати про свій здоровий фізичний і психологічний стан, створити усі належні умови для підтримки і бажання бути здоровим, а також підготовку до використання вмінь і навичок щодо зміцнення власного здоров'я.

У процесі організації змішаного навчання важливо звернути увагу саме на умови поліпшення здоров'я студентів, а саме:

- створення позитивного психологічного мікроклімату, який ефективно впливає на освітній процес та здоров'я студентів;

- використання новітніх методик та програм для подальшого збереження і зміцнення здоров’я студентів;

- створення інформаційного простору з питань збереження здоров'я студентської молоді;

- підвищення валеологічної культури студентів;

- підвищення рухової активності: фізкультхвилинки, ігри, руханки, пальчикова гімнастика, гімнастика для очей, години здоров'я;

- дотримування санітарно-гігієнічного режиму в гуртожитках: тепловий, повітряний режим, вологе прибирання.

Як зазначає Б. Максимчук, визначаючи цілі валеологічної освіти, необхідно пам'ятати, що досягти необхідної зрілості особистості студента, тобто гармонійного розкриття та розвитку всіх його потенціалів, можливо тільки за тієї умови, якщо в основу всього буде покладено навчання “мистецтву жити”, не завдаючи шкоди своєму здоров”ю. Головними “інструментами і орієнтирами повноцінного життя повинні стати: життєлюбність, воля, фізичне, психічне, репродуктивне здоров'я, позитивні емоції та розвинений інтелект" [5].

Підготовка студентів, що орієнтована на формування валеологічної культури, включає дві взаємозалежні частини: змістову (виховання валеологічної культури за наявності моральної самосвідомості особи) та методичну (навчання основа професійно-валеологічної діяльності).

Як зазначає Б. Максимчук, “формування валеологічної культури студента має включати, на наш погляд, валеологічну освіченість, свідомість, поведінку. Валеологічнна підготовка студентів повинна пронизувати всі дисципліни, починаючи з 1-ого курсу, і закінчуватися на випускному" [5].

Підтвердженням цього є погляд Н. Сєдової, яка підкреслює, що “на сучасному етапі знання стають основним капіталом, який регулює динаміку розвитку науки та виробництва, але яким би не був капітал знань нашого покоління, нашої молоді, ніщо не може бути важливішим за стан його здоров' я" [8].

Це потребує великих затрат часу, координації зусиль різних за фахом спеціалістів, але ця багатоаспектна, багатопланова проблема має бути розв'язана.

Зміст і форма процесу змішаного навчання повинні бути в міцній єдності, тому варто створювати якісно нові підходи до організації цього процесу. Валеологічна культура тісно пов'язана 3 інформаційною культурою, яка засвідчує розвиток умінь ефективного використання інформаційного середовища, навичок управління інформаційними ризиками, підвищення психологічної стійкості до негативних інформаційних впливів. На думку вчених, “під час вивчення дисциплін повинна приділятися увага питанню захисту від інформаційно-психологічного впливу на людину через технічні системи й засоби масової інформації, а також організаційним, оперативним, правовим і психологічним аспектам забезпечення інформаційної безпеки. Особливого висвітлення потребують питання санітарногігієнічних вимог до роботи з комп'ютером" [7].

Валеологічне виховання як невід'ємна складова професійної підготовки має входити до системи загальних організаційних і педагогічних заходів, які сприяють формуванню в майбутніх фахівців необхідних професійних якостей.

Висновки. Валеологічне виховання студентської молоді $є$ комплексом організаційно-педагогічних заходів, який охоплює такі структурні компоненти, як озброєння знаннями з валеології, формування почуттів і переконань, умінь і навичок валеологічної вихованості.

Перспективним напрямом подальших наукових досліджень буде вивчення проблеми ефективного використання студентами технічних спеціальностей валеологічних знань під час проходження виробничої практики.

\section{ЛІТЕРАТУРА}

1. Авдєєнко І. М. Сучасні підходи до розуміння поняття “культура здоров'я”. Педагогічні науки. Херсон: ХДУ, 2011. Вип. 59. С.165-169. 
2. Бойчук Ю. Д., Науменко Н. В. Підготовка майбутніх учителів до формування духовного здоров’я молодших школярів. Харків, 2018. С. 610.

3. Грибан В. Г. Валеологія: навчальний посібник. Київ : Центр навчальної літератури, 2005. $256 \mathrm{c}$.

4. Кофанов В. В. Формирование у студентов мотивации к здорову образу жизни. Педагогические науки. 2008. №3. С.173-178.

5. Максимчук Б. А. Валеологічна культура в системі професійної підготовки майбутнього вчителя. Педагогіка здоров'я. Харків, 2013. С.180-184.

6. Оржеховська В. М. Теоретико-методологічні засади формування здорового способу життя дітей і молоді. Валеологія: сучасний стан, напрямки та перспективи розвитку. Харків: ХНУ ім. В. Н. Каразіна, 2016. С. 138-143.

7. Петрюк С. Здоровий спосіб життя: роль технологій збереження здоров'я. Загальна теорія здоров'я $i$ здоров'язбереження: монографія / за ред. Ю.Д. Бойчука. 2017.С. 326327.

8. Сєдова Н. А. Формування інтересу до здорового способу життя у процесі професійної спрямованості сучасного фахівця. Актуальні проблеми навчання та виховання людей з особливими потребами : зб. наук. пр. Київ, 2015. №12(14). С.169-182.

9. Христова Т., Пюрко В., Казакова С. Стан здоровя студентів вищих навчальних закладів та шляхи його поліпшення. Загальна теорія здоров'я $i$ здоров'язбереження: монографія / за ред. Ю.Д. Бойчука. 2017. С.108-113.

10. Чепіль М. Теоретичні засади фізичного виховання дітей і молоді у Польщі (1918-1939 рр.). Молодь і ринок. Дрогобич, 2020. №3-4(182-183). C.6-12.

\section{REFERENCES}

1. Avdieienko, I. M. (2011). Suchasni pidkhody do rozuminnia poniattia "kultura zdorovia" [Modern approaches to understanding the concept of "health culture"]. Pedagogical sciences. Vol. 59. pp.165169. [in Ukrainian].

2. Boichuk, Yu. D. \& Naumenko, N. V. (2018). Pidhotovka maibutnikh uchyteliv do formuvannia dukhovnoho zdorovia molodshykh shkoliariv
[Preparing the future teachers for the formation of the spiritual health of primary school children]. Kharkiv, pp. 6-10. [in Ukrainian].

3. Hryban, V. H. (2005). Valeolohiia: navchalnyi posibnyk [Valeology: a textbook]. Kyiv, 256 p. [in Ukrainian].

4. Kofanov, V. V. (2008). Formirovanie u studentov motivatsii $\mathrm{k}$ zdorovu obrazu zhizni [The formation of the students' motivation for a healthy lifestyle]. Pedagogical sciences. No.3. pp.173-178. [in Russian].

5. Maksymchuk, B. A. (2013). Valeolohichna kultura v systemi profesiinoi pidhotovky maibutnoho vchytelia [Valeological culture in the system of professional training of future teachers]. Health education. Kharkiv, pp.180-184. [in Ukrainian].

6. Orzhekhovska, V. M. (2016).Teoretykometodolohichni zasady formuvannia zdorovoho sposobu zhyttia ditei i molodi [The theoretical and methodological principles of forming a healthy lifestyle of children and youth]. Valeology: current state, directions and prospects of development. Kharkiv, pp. 138-143. [in Ukrainian].

7. Petriuk, S. (2017). Zdorovyi sposib zhyttia: rol tekhnolohii zberezhennia zdorovia [Healthy living: the role of health technologies]. General theory of health and healthcare: a monograph. (Ed.).Yu.D. Boichuk. pp. 326-327. [in Ukrainian].

8. Siedova, N. A. (2015). Formuvannia interesu do zdorovoho sposobu zhyttia u protsesi profesiinoi spriamovanosti suchasnoho fakhivtsia [The formation of interest in a healthy lifestyle in the process of professional orientation of a modern specialist]. Actual problems of education and upbringing of people with special needs: coll. Science. works. Kyiv, no.12(14). pp.169-182. [in Ukrainian].

9. Khrystova, T., Piurko, V. \& Kazakova, S. (2017). Stan zdorovia studentiv vyshchykh navchalnykh zakladiv ta shliakhy yoho polipshennia [The state of health of students of higher educational institutions and ways to improve it]. General theory of health and healthcare: a monograph. (Ed.). Yu.D. Boichuk. pp.108-113. [in Ukrainian].

10. Chepil, M. (2020). Teoretychni zasady fizychnoho vykhovannia ditei i molodi u Polshchi (1918-1939 rr.). [The theoretical principles of physical education of children and youth in Poland (19181939)]. Youth \& market. Drohobych, no.3-4(182183). pp.6-12. [in Ukrainian].

Стаття надійшла до редакції 15.12.2020

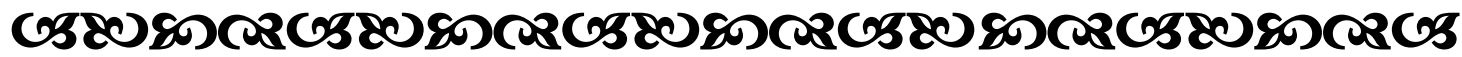

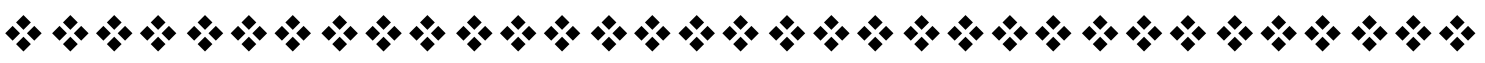

